Boise State University

ScholarWorks

Kinesiology Faculty Publications and Presentations

Department of Kinesiology

$1-1-2013$

\title{
Developing an Instrument to Measure Physical Activity Related Self-Worth in Women: Rasch Analysis of the Women's Physical Activity Self- Worth Inventory (WPASWI)
}

Jennifer Huberty

University of Nebraska at Omaha

Jamie Vener

Southern Oregon University

Yong Gao

Boise State University

Justin Matthews

University of California

Lynda Ransdell

Boise State University

See next page for additional authors

NOTICE: this is the author's version of a work that was accepted for publication in Psychology of Sport and Exercise. Changes resulting from the publishing process, such as peer review, editing, corrections, structural formatting, and other quality control mechanisms may not be reflected in this document. Changes may have been made to this work since it was submitted for publication. A definitive version was subsequently published in Psychology of Sport and Exercise, 14(1), 2012. DOI: 10.1016/j.psychsport.2012.07.009 
Authors

Jennifer Huberty, Jamie Vener, Yong Gao, Justin Matthews, Lynda Ransdell, and Steriani Elavsky 


\title{
Developing an Instrument to Measure Physical Activity Related Self-Worth in Women: Rasch Analysis of the Women's Physical Activity Self-Worth Inventory (WPASWI)
}

\author{
Jennifer Huberty \\ University of Nebraska at Omaha \\ Jamie Vener \\ Southern Oregon University \\ Yong Gao \\ Boise State University
}

\author{
Justin Matthews \\ University of California \\ Lynda Ransdell \\ Boise State University \\ Steriani Elavsky \\ Pennsylvania State University
}

\begin{abstract}
Objectives: The objective of this study is to report on the development of an instrument to assess non-physical aspects of physical activity (PA) -related self-worth (SW).

Methods: Three hundred thirty five women (mean age $=36.69 \pm 15.94 \mathrm{yrs}$, BMI $=24.87 \pm$ 4.56) completed the Women's Physical Activity Self-Worth Inventory (WPASWI), General SW Scale, and a PA Questionnaire. Rasch analysis was used to evaluate the WPASWI.

Results: Three PA-related SW subscales were identified: PA Knowledge (16 items), PA Emotional (13 items), and PA Social (8 items). Rasch analysis supported construct validity, and items demonstrated acceptable internal consistency (Cronbach's alpha $=.90, .87$ and .72 ) and test re-test reliability $(r=.79, .70, .81)$. Women who reported regular PA participation had higher PA Knowledge, PA Emotional, PA Social, and General SW than those who reported some or no PA $(p<.01)$ and correlations between Knowledge, Emotional, and Social SW subscales and General SW were .207, .130, and .220, respectively. PA Knowledge and PA Emotional SW had stronger correlations with PA $(r=.344, .273$, respectively) than did General SW $(r=.133)$.

Conclusions: The WPASWI demonstrated good internal consistency, reliability, construct validity and a stronger relationship with PA than a General SW instrument.
\end{abstract}

Keywords: tool, assessment, methods

\section{Introduction}

Fewer than $15 \%$ of women in the United States are meeting recommendations for physical activity (PA) (at least 150 minutes of moderate intensity activity per week) and this has not changed in the last decade (U.S. Department of Health and Human Services [USDHHS], 2008; Ainsworth, 2000; Centers for Disease Control and Prevention [CDC, 2010]). Psychological and behavioral strategies have been useful in promoting physical activity (PA) participation in women and there is a considerable amount of evidence that supports the relationship between self-worth (SW) and PA participation, especially in women (Elavsky, 2009; Huberty, Vener, \& Sidman, 2008a; McAuley, Mihalko, \& Bane, 1997; McAuley \& Blissmer, 2000a; McAuley, Blissmer, Katula, Duncan, \& Mihalko, 2000b; McAuley, Elvasky, Motl, Konopack, Hu, \& Marquez, 2005a; Elavsky \& McAuley, 2007; Gothe, Mullen, Wojcicki, Mailey, White, \& Olson et al., 2011; Spence, McCannon, \& Poon, 2005).

Global self-worth (or self-esteem) is broadly defined as a sense of self-regard towards oneself, encompassing personal judgments of worthiness, self-acceptance, and a sense of competence (Coopersmith, 1967; Harter, 1985). As such, it is considered a focal aspect of psychological health and well-being (Rosenberg, 1965; Wells \& Marwell, 1976). Self-worth is also hierarchical and multidimensional. Because it represents the evaluative aspect of selfconcept, self-worth is thought to reflect the structure of self-concept which has been traditionally divided into physical, academic/knowledge, social, and emotional domains (Marsh \& Shavelson, 1985; Wells \& Marwell, 1976). 
NOTICE: this is the author's version of a work that was accepted for publication in Psychology of Sport and Exercise. Changes resulting from the publishing process, such as peer review, editing, corrections, structural formatting, and other quality control mechanisms may not be reflected in this document. Changes may have been made to this work since it was submitted for publication. A definitive version was subsequently published in Psychology of Sport and Exercise, 2012. DOI: 10.1016/j.psychsport.2012.07.009

The Exercise Self-Esteem Model specifies that physical changes that ensue from exercise participation influence global physical self-worth through its subdomains (physical condition, attractive body, and strength) and that this brings about changes in global self-worth (Sonstroem \& Morgan, 1989; Sonstroem, Harlow, \& Josephs, 1994; Gothe et al., 2011). McAuley and colleagues have provided much of the evidence for the relationship among PA and global self-worth through the physical domain (McAuley et al., 2005a; McAuley, Blissmer, Katula, Duancan, \& Mihalko, 2005b) and have reported that effects of PA are stronger on physical self-worth than global self-worth.

Physical activity participation however impacts a broad range of self-perceptions, including self-perceptions within the emotional, social and knowledge domains, especially in women (Strelan, Mehaffey, \& Tiggeman, 2003; Segar, Eccles, \& Richardson, 2008; Ryan, 2008), but these non-physical domains have not been thoroughly explored. Marsh's Self-Description Questionnaires (SDQ, SDQ II and SDQ III; Marsh, 1988a; Marsh, 1988b; Marsh, 1988c), have assessed self-evaluation across multiple domains, including both the physical and non-physical (Academic, Emotional, Social) dimensions. The SDQ instruments have been used both to measure self-concept and self-worth, but none of them measure non-physical domains of self-worth specifically in the context of physical activity participation, and all have been used and validated primarily among adolescent and young adult populations (Marsh, 1988c). PA researchers commonly use instruments developed for measurement in psychology and education rather than those developed for PA settings (Welk, 2002), however, PA-specific measures are likely to be more sensitive and informative when it comes to evaluating effects of PA. That is, just as PA effects on global self-worth are thought to be mediated by physical self-worth because it encompasses a range of physical self-perceptions (e.g., strength, condition, of body attractiveness subdomain) that can be changed through physical activity (Sonstroem \& Morgan, 1989), so should PA-induced changes in non-physical domains such as knowledge, social, or emotional domains mediate its impact on global self-worth. An instrument sensitive enough to measure such effects should explicitly measure these effects in the context of PA participation (Welk, 2002).

Ryan (2008) utilized The Exercise Self-Esteem Model and reported that substantial variation in self-worth remained unexplained even after accounting for pathways through the physical domain, suggesting that PA may impact SW through non-physical aspects of SW related to PA (Sonstroem \& Morgan, 1989). Ryan suggested that PA programs that have social components (e.g. buddy groups) or intellectual components (e.g. education) may enhance global SW through academic or social aspects of SW related to PA. For example, in a study by Huberty and colleagues (2009) women who had participated in a physical activity book club (Women Bound to Be Active) reported that their increased PA participation during and after the program was related to the knowledge they had gained about how to incorporate PA into their daily lives, how to use self-monitoring techniques, and knowledge about the importance of PA. In the same study, women reported that being active had mental and emotional benefits, including getting more out of life and having more energy.

Despite these promising findings related to how self-perceptions in the non-physical domains may influence PA in women, to date, there are no instruments that collectively identify and measure non-physical PA domains and provide subscale scores of these components for adult females. We believe that having the ability to collectively measure these gender-specific non-physical domains will improve our understanding of the factors that moderate physical activity participation in women. For example, measuring Emotional SW as it relates to PA would include items about a woman prioritizing herself over others to participate in PA. Previous research (Huberty, Ransdell, Sidman, Flohr, Shultz, Grosshans et al., 2008b) has found that women tend to prioritize themselves lower than others, which may negatively impact their ability to participate in PA as well as their self-worth. Having the ability to measure that dimension is important because it is possible that Emotional SW is a more powerful mediator of PA and Global SW in women than in men, but questionnaires are needed to measure that dimension. Measuring Social SW as it relates to PA would include questions about whether or not a woman needs friends and family to support her commitment to exercise. Previous research suggests that women are more influenced by social support than men when it comes to PA participation (Sallis, Hovell, \& Hofstetter, 1992). Developing an effective measure of social SW might improve our ability to determine whether social SW is a mediator of PA participation and Global SW. Finally, measuring Knowledge SW as it relates to PA would assess how knowing how to plan a physical activity program or learning more about PA makes a woman feel about herself. The relationship between Knowledge and PA is equivocal in many populations (Moore, Fulton, Kruger, McDivitt, 2010), but that may be because better measures are needed or because it has not been measured in conjunction with other non-physical domains of PA. 
NOTICE: this is the author's version of a work that was accepted for publication in Psychology of Sport and Exercise. Changes resulting from the publishing process, such as peer review, editing, corrections, structural formatting, and other quality control mechanisms may not be reflected in this document. Changes may have been made to this work since it was submitted for publication. A definitive version was subsequently published in Psychology of Sport and Exercise, 2012. DOI: 10.1016/j.psychsport.2012.07.009

These non-physical domains, as described above, have independently been identified as mediators of a woman's participation in physical activity, and possibly her Global SW. There is a need for an instrument that could collectively identify each component of non-physical domain-specific self-worth into a subscale score. If this scale is designed specifically for women, then gender-specific information could be integrated into Sonstroem's model of Exercise Self-Esteem, which could advance the science of how psychology impacts PA participation and global SE in women.

Given these knowledge gaps and limited instruments for research in this area, the purpose of this study was to report on the development of an instrument designed to measure the non-physical domains of SW (Academic, Emotional, and Social) related to PA and determine the relationship of these domains of SW to PA participation in women. Information from this study and the use of this new questionnaire will help researchers better understand how PA impacts SW and which domains to target in PA interventions to yield optimal improvements in SW and PA participation in women.

\section{Methods}

\section{Participants}

Women $(\mathrm{N}=335)$ participated in this study if they were between the ages of 20-80 years and able to read and understand English. This age range was chosen because we sought to develop an instrument that could be used across a wide range of adult women.

\section{Measures}

All women completed a demographic questionnaire, the Women's Physical Activity and Self-Worth Inventory (WPASWI), General Self-Worth Scale of the Adult Self-Perception Profile, and the Godin Leisure-Time Exercise Questionnaire.

Demographic questionnaire. The demographic questionnaire was modified from Howley \& Franks (1992), to obtain age, ethnicity, income, level of education, marital status, occupation, and self-reported weight and height.

Development of the WPASWI. The WPASWI was developed through a multi-stage process which included (1) item development and content validation, (2) item refinement and scale reduction, and (3) pilot testing. Specifically, the items for the WPASWI were developed by: 1) a review of the literature related to SW and previously developed self-evaluation instruments based on these constructs, 2) modifications (rewritten and new items) from approximately 47 items from the MSDQIII developed by Herb Marsh and based upon adolescent self-worth (Conrad $\&$ Smith, 2004), and 3) preliminary (qualitative and quantitative) data gathered by the research team from the Women Bound to Be active program (Huberty et al., 2008a; Huberty, Vener, Ransdell, Schulte, Budd, \& Gao, 2010; Huberty, Vener, Schulte, Roberts, Stevens, \& Ransdell, 2009a). As part of content validation, the initial WPASWI was critically reviewed by experts who have developed and implemented PA interventions in women and have experience in item development and selection (Huberty, Vener, Waltman, Ott, Twiss, \& Gross et al., 2009b; Ransdell, Dinger, Huberty, Miller, 2009). The items were modified based on the expert comments and subsequently tested in a sample of 348 women (unpublished data). As part of the pilot testing, exploratory factor analysis was used to arrive at a 42-items version of the WPASWI, which assessed three domains of PA-related SW including PA Knowledge (Academic), PA Social, and PA Emotional. The "academic" domain from Marsh's questionnaire was renamed "knowledge" for the purposes of this research (Marsh, 1988c). Operational definitions for items developed were as follows: 1) for the PA Knowledge domain, items were written to assess self-worth relative to knowledge about physical activity, 2) PA Emotional items represented one's perceived self-worth related to the ability to deal with life stressors and various emotional challenges associated with physical activity, and 3) PA Social items represented a person's self-worth as it relates to his or her interactions with others in the context of physical activity. A Likert scale was used for each item, ranging from 1 to 4: strongly disagree (likert score $=1$ ), disagree (likert score $=2$ ), agree (likert score $=3$ ), and strongly agree (likert score $=4$ ). A 4-point Likert scale was used in this study because during the pilot testing of the WPASWI using a 5-point Likert scale, very low frequency $(<5)$ for the selection of Category 1 was observed for most of items. Additionally, preliminary Rasch analysis showed a disordered item response format, suggesting the 5-point Likert scale was not a balanced response format and may not be appropriate for the WPASWI. Therefore, Categories 1 and 2 were combined to yield a 4-point Likert scale. 
NOTICE: this is the author's version of a work that was accepted for publication in Psychology of Sport and Exercise. Changes resulting from the publishing process, such as peer review, editing, corrections, structural formatting, and other quality control mechanisms may not be reflected in this document. Changes may have been made to this work since it was submitted for publication. A definitive version was subsequently published in Psychology of Sport and Exercise, 2012. DOI: 10.1016/j.psychsport.2012.07.009

The final stage of refining the WPASWI also involved conducting a focus group to acquire final feedback on the comprehensibility and readability of the 42-item WPASWI. Ten women were recruited from the local community. The focus group provided feedback on relevance of items, format, layout, wording of items, ease of administration, and any additional content areas that they felt were essential for assessing women's PA Knowledge, PA Emotional, and PA Social SW. The WPASWI was refined based on the focus group's feedback, which resulted in an additional 5 items for a total pool of 47 WPASWI items. The validity and reliability of the 47-item version of the WPASWI was tested in this study.

General Self-worth. SW was assessed using the General Self-Worth Scale of the Adult Self-Perception Profile (Messer, 1986). This scale measures one's global perceptions of SW independent of any particular domain. A sample question asked, "Some adults are dissatisfied with themselves BUT other adults are satisfied with themselves." Six items are listed on this questionnaire with answers ranging from "really true for me" to "sort of true for me". Higher scores on the questionnaire indicate higher SW. The internal consistency (Cronbach's alpha) reported for this scale was .87 and it is reliable and valid for adult women (Messer, 1986).

Godin Leisure-Time Exercise Questionnaire (GLTEQ). Using this self-report instrument, participants were asked to complete a four-item query of usual leisure-time exercise habits. The questionnaire assessed how many times on average during a 7-day period an individual participated in more than 15 minutes of strenuous, moderate, and mild exercise (Godin 1 score). It also assessed how often an individual engaged in any regular activity (long enough to work up a sweat) during a week. Weekly frequencies of strenuous, moderate, and light activities were calculated for the total amount of weekly leisure activity (Godin 2 score). The Godin 1 scoring is positively valenced (higher scores indicate more PA); while the Godin 2 scoring is negatively valenced (higher scores indicate less PA). This questionnaire is reliable and valid for use in adult populations (Godin \& Shephard, 1985).

\section{Procedures}

The study was approved by an Institutional Review Board at a Midwestern University. Women were asked to complete the above four questionnaires in this study. Graduate students and professors at four universities in the United States (Nebraska, Idaho, Oregon, and California) distributed over 600 questionnaires to women who met the eligibility criteria (between the ages of 20-80 years and able to read and understand English). Distribution included but was not limited to grocery stores, hair salons, book stores, coffee shops, worksites, sporting events and competitions and school district faculty and staff email lists. When women were asked to participate in the study and they verbally consented, they were given the option to complete the questionnaires on the spot or return them via mail (prepaid addressed envelope provided). If they chose to mail the questionnaires, they were informed that they would be contacted one time to remind them to complete and return the questionnaires. All participants were informed that they may be randomly chosen to complete the WPASWI one week later. If a woman was chosen to complete the WPASWI again, the questionnaires were mailed to her to return in a prepaid addressed envelope. Participants were contacted via phone to remind them to complete and return the questionnaires within one week.

\section{Data Analysis}

The Rasch rating scale model was selected to evaluate the responses from the WPASWI. The Rasch model is an advanced modern measurement theory that has been successfully used in social, educational, psychological and health research for instrument development or refinement (Bezruczko, 2005; Conrad \& Smith, 2004; Duncan, Bode, Min Lai, \& Perera, 2003; Tennant, McKenna, \& Hagell, 2004), and has recently been introduced to PA and sport sciences (Strauss, Busch, \& Tenenbaum, 2007; Strauss, Busch, \& Tenenbaum, 2012). The Rasch model has several significant advantages (Bond \& Fox, 2007; Rasch, 1960; Rasch, 1980) over classic test theory methods. In the Rasch model, a person's response to an item is the result of an interaction between that person's ability (e.g., level of physical activity participation) and item difficulty (e.g., difficulty of a physical activity task). Therefore, given an item difficulty level, higher ability individuals will more likely pass an item (or do a task) than lower ability individuals; additionally, easier items will more likely be passed than more difficult items (Tennant, McKenna, \& Hagell, 2004; Bond \& Fox, 2007; Rasch, 1960; Rasch, 1980). This means that estimations of item difficulty are independent of the sample of participants, and estimations of person ability are independent of items used, which overcomes the major limitations of the classic test theory (Bond \& Fox, 2007). The term "person ability" is generally used in Rasch model to describe the latent trait that an instrument is intent to measure (PA-related selfworth in this study). When fitting data to the Rasch model, both the person ability parameter and item difficulty 
NOTICE: this is the author's version of a work that was accepted for publication in Psychology of Sport and Exercise. Changes resulting from the publishing process, such as peer review, editing, corrections, structural formatting, and other quality control mechanisms may not be reflected in this document. Changes may have been made to this work since it was submitted for publication. A definitive version was subsequently published in Psychology of Sport and Exercise, 2012. DOI: 10.1016/j.psychsport.2012.07.009

parameter are placed on a common metric (Bond \& Fox, 2007). Such linking of item difficulty to person ability in the Rasch model enables the researcher to examine whether participants in a study respond to a measure in a consistent, logical manner (Bond \& Fox, 2007).

To determine how well the data fit the Rasch model, Rasch goodness-of-fit statistics (e.g., Infit and Outfit statistics); are typically used (Wright \& Linacre, 1994). Infit and Outfit statistics values for an item close to 1 are considered a good model fit, while values greater than 1.3 or less than 0.7 are considered a misfit (Bond \& Fox, 2007). Infit and Outfit values for an item greater than 1.3 indicate inconsistent performance while values less than 0.7 show too little variation. From an instrument development and refinement point of view, if all the items in an instrument are good fit items, this provides evidence of construct validity (Baghaei, 2008; Smith, 2001).

Construct validity can also be supported through a principal components analysis (PCA) of the residuals (Wright \& Stone, 1988). Under Rasch model consideration, a measure is thought to assess a single construct (i.e., unidimensionality), which is a fundamental requirement of construct validity (Rasch, 1960; Rasch, 1980). A measure is considered unidimensional if most of the variance in the data is explained by the Rasch model and the unexplained variance by the residual from the Rasch model (i.e., the contrasts to the principal component) is less than 2.0 Eigenvalue units (Linacre, 2009). Rasch analysis provides the item-person map, which displays the relative position of person ability levels and item difficulties on the same common metric (Linacre, 2009). The item-person map can be used to examine how well the difficulty of the items in a measure matches the ability of the study sample. When there are large distances between items on the metric, it indicates that the measure is less able to discriminate between person abilities at these points.

Rasch analysis also provides person (and item) separation and reliability statistics for the evaluation of the internal consistency of a measure (Wright \& Stone, 1988). The person separation index indicates the range of ability scores being measured along the common metric with a value of 2.0 being the minimally accepted level and the higher, the better. The person reliability statistic is equivalent to the traditional Cronbach's alpha, with a value close to 1.00 representing excellent internal consistency (Linacre, 2009; Wright \& Stone, 1988). The item separation index shows the spread of the item difficulty levels along the common metric. Item reliability indicates the level of confidence that the items would have the same respective order in another sample of participants (Duncan et al., 2003).

Whether or not a response format utilized in a measure is appropriate can also be examined using Rasch analysis. Appropriate response format should show all items have ordered response thresholds, and consecutive thresholds demonstrate an increase along the underlying trait being measured (i.e., women who selected $4=$ strongly agree should have higher SW than whose who selected 3 = agree for an item in this study). If not, it is an indication of "disordered" thresholds and a common solution is to combine adjacent response categories (Andrich, De Jong, \& Sheridan, 1997).

In this study, the PCA was first conducted to determine whether the WPASWI measures a single underlying construct (unidimensionality). When PCA indicated multiple dimensions in WPASWI data, separate Rasch analyses were conducted on each dimension. For each dimension, misfit items were removed and Rasch analysis was rerun. The process was iterated until all remaining items in each dimension exhibited good model fit. When the items for each dimension were selected, an investigation of the distribution of responses for each item and item thresholds was conducted to assess the suitability of the 4-point Likert response format used in the WPASWI. Rasch analysis was performed using WINSTEPS 3.69 software. The item difficulty levels along with fit statistics, item-person maps, and Rasch reliability statistics were reported for the final WPASWI domains. To determine if self worth scores differed by PA levels, descriptive and inferential statistics ANOVA were computed. Correlation analysis was conducted to determine the relationships between WPASWI ability estimates and GSW and PA measures.

\section{Results}

\section{Sample Characteristics}

Out of the 335 women (mean age $=36.69 \pm 15.94 \mathrm{yrs}, \mathrm{BMI}=24.87 \pm 4.56$ ) who completed the study questionnaires, the majority were Causation/White (92.4\%). About $45 \%$ of the women indicated they often participated in regular moderate to vigorous leisure time PA during a typical 7-day period, $43 \%$ participated in some leisure time PA, and $12 \%$ indicated they never participated in regular leisure PA. 
NOTICE: this is the author's version of a work that was accepted for publication in Psychology of Sport and Exercise. Changes resulting from the publishing process, such as peer review, editing, corrections, structural formatting, and other quality control mechanisms may not be reflected in this document. Changes may have been made to this work since it was submitted for publication. A definitive version was subsequently published in Psychology of Sport and Exercise, 2012. DOI: 10.1016/j.psychsport.2012.07.009

Seventy women (mean age $=35.31 \pm 15.37 \mathrm{yrs}, \mathrm{BMI}=25.07 \pm 3.83$ ) completed test-retest evaluations and the majority were Causation/White $(88.6 \%)$. About $52.2 \%$ of the women indicated they often participated in regular moderate to vigorous leisure time PA during a typical 7-day period, 36.2\% participated in some leisure time PA, and $11.6 \%$ indicated they never participated in regular leisure time PA. No statistical differences were found between the demographics of the retest sample and the overall sample, $\mathrm{p}>0.05$.

\section{Dimensionality, Fit Statistics and Item-Person Maps of the WPASWI}

Initially, all 47 items of the WPASWI were included in a single Rasch model, and the PCA of the residuals was performed to assess dimensionality of the data. The PCA results revealed multiple dimensions in the data. The first principal component exhibited an eigenvalue of 8.8 (larger than the recommended 2.0; Linacre, 2009); and explained $11.7 \%$ of the variance in the data, with 14 items in this dimension mostly focusing on PA Social SW. After removing these 14 items, a subsequent PCA of the residuals for the remaining 33 items in the WPASWI indicated further multidimensionality: an eigenvalue of 3.7 explaining $5.8 \%$ of the variance in the data with 17 items mostly focusing on PA Emotional SW. A further PCA of the residuals for the remaining 16 items in the WPASWI revealed unidimension focusing on PA Knowledge SW, with an eigenvalue less than 2.0. Together, the results of these PCAs supported the original three conceptual-subscale structure specified by the developers of the WPASWI: PA Knowledge SW, PA Emotional SW, and PA Social SW. Rasch analysis was then conducted on each dimension separately, and the results for each dimension were reported in the following section:

PA Knowledge SW. No misfit items were identified in the dimension of PA Knowledge SW due to Rasch item misfit statistics and measurement redundancy (i.e., Infit and Outfit values were out of the range of .7 to 1.3; Bond \& Fox, 2007); and all 16 items had good item-model fit in the PA Knowledge SW subscale. Table 1 (upper panel) shows the estimated item difficulties with standard errors, and fit statistics from Rasch analysis for the PA Knowledge SW dimension. PA Emotional SW. Four misfit items were identified in the dimension of PA Emotional SW according to Infit and Outfit statistics. Two items (Item 19 "I have a more positive attitude about myself when I am participating in a physical activity regimen" and Item 25 "I believe that my physical activity is a positive influence on my quality of life") had Outfit statistics of 0.63 and 0.55 ) indicating measurement redundancy. Two items (Item 33 "I believe that being physically active helps me to interact with others more positively" and Item 48 "Daily activity doesn't make me feel better about myself") had larger Infit (1.32 and 1.46, respectively) and Outfit values (1.32 and 1.57, respectively), indicating unexpected response patterns. Removal of these four items improved the fit of the PA Emotional SW subscale to Rasch model. Item difficulty estimates with standard errors and fit statistics of the remaining 13 good fit items are provided in Table 1 middle panel.

PA Social SW. Six misfit items with Infit and Outfit values greater than 1.3 were identified in the dimension of PA Social SW and were removed. Two example misfit items are listed here: Item 40 ("I still feel good about myself when I haven't stayed on my physical activity program") and Item 41 ("It doesn't bother me when friends tell me I need to be more active"). Table 1 (lower panel) provides the estimated item difficulties with standard errors, and fit statistics for the remaining 8 good items in PA Social SW.

\section{[INSERT TABLE 1 ABOUT HERE]}

The item-person maps in Figure 1 from Rasch analysis display the location and distribution of both the items in each dimension with good fit statistics and the women's SW on the same common logit metric. On each map, the persons with higher SW and most difficult items were placed on the top of the map, and the numeric scale is shown on the left with persons and items charted on the right side. To adequately reflect the item difficulty spread, items in each figure are presented with three step difficulties: the average item difficulties (the middle item group), and two difficulty thresholds (upper and lower item groups). The thresholds separate the chance of scoring a higher rating (e.g., category 2) from the chance of scoring an adjacent lower rating (e.g., category 1).

For PA Knowledge SW (Figure 1a), item difficulty ranges from -5 to 5.2 logits while person ability spreads from 1.9 to 6.7 logits; and about $5 \%$ of the sample at the higher end of person ability is not covered by the item difficulty range. For PA Emotional SW (Figure 1b), the difficulty spread of the items is between -6 and 6.4 logits, while person ability spreads from -2 to 7.45 logits and $19 \%$ of the sample at the higher end of ability is not covered by the item difficulty range. For PA Social SW, the map (Figure 1c) indicates a relatively good match between item 
NOTICE: this is the author's version of a work that was accepted for publication in Psychology of Sport and Exercise. Changes resulting from the publishing process, such as peer review, editing, corrections, structural formatting, and other quality control mechanisms may not be reflected in this document. Changes may have been made to this work since it was submitted for publication. A definitive version was subsequently published in Psychology of Sport and Exercise, 2012. DOI: 10.1016/j.psychsport.2012.07.009

difficulty (ranging between -3.6 and 3.8 logits) and person ability (ranging between -3.47 and 4.91 logits), and only $3.6 \%$ of the sample at the very higher and lower ends of ability is not covered by the item difficulty range.

\section{[INSERT FIGURE 1 ABOUT HERE]}

\section{Reliability}

The separation index for person measures was 2.99, with reliability of 0.90 for the PA Knowledge SW subscale; and for the PA Emotional SW subscale, the separation index for person measures was 2.55, with reliability of 0.87 . This indicates that the PA Knowledge SW and PA Emotional SW subscales have high internal consistency. For the PA Social SW subscale, the separation index for person measures was 1.61, with reliability of 0.72 , indicating acceptable internal consistency. The item separation indices indicates were 5.91 for the PA Knowledge SW subscale, 8.13 for the PA Emotional SW and 5.93 for the PA Social SW subscale, which are all above the minimum index score of 2.0 (Linacre, 2009). The item reliability coefficients for the three subscales are equal to 0.97 or above, indicating a high degree of confidence that item difficulty estimations would be in the same order in another sample of participants. In addition to Rasch separation indexes and reliability statistics, test-retest reliability was also examined through traditional correlation analysis and the results showed $(r=.79, .70, .81)$ for PA Knowledge SW, PA Emotional SW and PA Social SW, respectively.

\section{Response Format Assessment}

The appropriateness of the 4-point Likert format (e.g., 1=Strongly Disagree to 4=Strongly Agree) used in this study was assessed. If the response format is appropriate, persons who selected Category 2 (Disagree) on an item should have higher SW than persons who selected Category 1 (Strongly Disagree). Thus, Rasch-Andrich threshold for Category 2 should be larger than the threshold for Category 1 (Im, Lee, Chee, Stuifbergen, \& eMAPA research team, 2011). Rasch analysis of the WPASWI subscales showed both the average measures and Rasch threshold estimates (i.e., step difficulty) were ordered (see Table 2 for details) (Andrich et al., 1997). Therefore, the use of the 4-point Likert response format in the instrument is appropriate.

\section{[INSERT TABLE 2 ABOUT HERE]}

\section{Relationships between SW Subscales, GSW and PA}

The ability estimates of the participants' PA Knowledge SW, PA Emotional SW and PA Social SW were examined and are reported in Table 3 .Values are presented overall and by regular leisure time PA participation and weight category. Women who often participated in regular leisure-time PA during a typical 7-day period had significantly higher PA Knowledge SW and PA Emotional SW than those who only participated in regular leisure-time PA some days $(p<0.005)$ and those who never participated in regular leisure-time PA $(p<0.005)$. Women who reported some regular leisure-time PA participation also had significantly higher PA Knowledge SW $(p=0.005)$ and PA Emotional SW $(p=0.042)$ than those who never participated in regular leisure-time PA. Women who participated in regular leisure-time PA often or some days in a 7-day period also had significantly higher PA Social SW than those who never participated in leisure-time PA, $p=0.004$ and $p=0.026$, respectively.

\section{[INSERT TABLE 3 ABOUT HERE]}

Table 4 presents the Pearson correlations between participants' PA Knowledge SW, PA Emotional SW and PA social SW ability estimates and GSW and PA. There were low correlations between all subscales (PA Knowledge, PA Emotional, PA Social) and the General SW Scale (Pearson $r=.207, .130$, and .220). Pearson correlations of PA Knowledge and PA Emotional SW with PA were .344 and .273, respectively, and the correlation between General SW and PA was .133. Steiger's Z tests (Meng, Rosenthal, \& Rubin, 1992) were conducted to compare correlation coefficients of PA Knowledge, Emaotional SW and General SW with PA within this sample and the results indicated PA Knowledge and Emotional SW had significantly stronger correlations with PA than did General SW with PA, with Steiger's $Z=3.09, \mathrm{p}<0.01$ for the comparison between the correlations of Knowledge SW and General SW with PA, and Steiger's $Z=1.94, p<0.05$ for the comparison between the correlations of Emotional SW and General SW with PA. 
NOTICE: this is the author's version of a work that was accepted for publication in Psychology of Sport and Exercise. Changes resulting from the publishing process, such as peer review, editing, corrections, structural formatting, and other quality control mechanisms may not be reflected in this document. Changes may have been made to this work since it was submitted for publication. A definitive version was subsequently published in Psychology of Sport and Exercise, 2012. DOI: 10.1016/j.psychsport.2012.07.009

\section{[INSERT TABLE 4 ABOUT HERE]}

\section{Discussion}

The purpose of this study was to report on the development of an instrument (WPASWI) designed to assess nonphysical aspects of SW related to physical activity (PA Knowledge, , PA Emotional, PA Social). A secondary purpose was to link these non-physical domains to PA participation in women. The final WPASWI includes 37 good fit items with evidence of content validity, initial support for construct validity, acceptable internal consistency and test-retest reliability. The Knowledge SW and Emotional SW of the WPASWI in this study also demonstrate stronger associations with PA as compared to the association between the general SW instrument and PA. This is the first study to formally test the psychometric properties of a SW instrument that assesses self-perceptions in nonphysical domains of SW related to PA participation. This is also one of the few studies to use the Rasch model for instrument development in PA promotion research (Bezruczko, 2005; Conrad \& Smith, 2004; Duncan et al., 2003, Tennant et al., 2004).

The content validity of the WPASWI was supported by an extensive literature review in addition to discussions conducted by experts in the fields, focus groups and pilot testing. .The findings reported here are consistent with the intended design of the instrument to include non-physical SW domains related to PA and provide initial support for construct validity of this instrument.

Rasch analysis indicated that the WPASWI demonstrated three subscales with good fit items for each which included: PA Knowledge SW (16 items), PA Emotional SW (13 items) and PA Social SW (8 items), which support construct validity of WPASWI. In the PA Knowledge SW subscale, one of the most difficult items was "I am good at developing physical activity programs for myself" and one of the least difficult items was "I like learning about physical activity and exercise". These items reflect different stages of knowledge accumulation. Learning about physical activity and exercise can be fun and is essentially simple (representing declarative, lower-level knowledge), but developing a PA program (representing procedural, higher-level knowledge) may require more specific knowledge about PA-- which a majority of adult women may not have (Im et al., 2011). Although beliefs, attitudes, and perceptions about PA and their relationship to PA participation in women have been studied extensively (Eyler, Matson-Koffman, Vest, Evenson, Sanderson, \& Thompson et al., 2002a), knowledge about PA and its relationship to PA has not. A woman's knowledge about the fundamentals of PA and/or exercise (i.e., frequency, intensity, and type) may provide women a sense of empowerment to be successful at PA. In a qualitative follow-up study to a book club PA intervention, women reported that their increased knowledge (more aware about how to be active) was one of the most important attributes of their participation in the program (Huberty, et al., 2010). In another study, women reported they had ample information about PA via books, internet, but they needed in-depth information; topics detailing when or how to exercise and if what they were doing was the best for them (Im et al., 2011). More research related to knowledge about PA and its relationship to PA related SW is needed. The WPASWI may help health promotion professionals determine this relationship during their interventions.

For the PA Emotional SW subscale, two misfit items "I have a more positive attitude about myself when I am participating in a physical activity regimen" and "I believe that my physical activity is a positive influence on my quality of life" were easy items and had small Outfit values. Use of the term "positive" could have created bias, such that participants were inclined to agree or strongly agree with the statement, resulting in less variation in the responses, providing little useful information regarding their PA Emotional SW. Two other misfit items "I believe that being physically active helps me to interact with others more positively", and "Daily activity doesn't make me feel better about myself" had large Outfit values. Physical activity and daily activity could have been interpreted differently by the respondents. For example, daily activity may have been interpreted as activity in which women are taking care of others such as household chores whereas physical activity could have been interpreted as exercise or something women get to do for themselves. This may have impacted their PA Emotional SW responses. Among the 13 good fit Emotional SW items, one of the easiest was "If I take time to take care of myself I will be a better mother, wife, friend and daughter" and the most difficult item was "Creating a supportive environment related to physical activity helps me to feel good about myself". Research suggests that women understand the importance of taking care of themselves and their quality of life through participation in PA and that this may reflect positively onto others in their lives (Huberty, et al., 2008a; Huberty et al., 2009a; Eyler, Brownson, King, Brown, \& Donatelle, 1997). However, this knowing and desire may not always translate to actual PA participation (Huberty, et al., 2008). The item related to the concept of creating a supportive environment is a difficult item because women may 
NOTICE: this is the author's version of a work that was accepted for publication in Psychology of Sport and Exercise. Changes resulting from the publishing process, such as peer review, editing, corrections, structural formatting, and other quality control mechanisms may not be reflected in this document. Changes may have been made to this work since it was submitted for publication. A definitive version was subsequently published in Psychology of Sport and Exercise, 2012. DOI: 10.1016/j.psychsport.2012.07.009

not know what a supportive environment looks like, what it means, or the steps to take to create one. Additionally, women may need a certain sense of self in order to take the initiative to create one (Huberty, et al., 2008a; Huberty et al., 2009a; Huberty et al., 2009b; Huberty et al. in press). More research in this area is warranted. Instruments such as the WPASWI may help health promotion professionals better design interventions for enhancing emotional self-perceptions that may lead to higher PA participation.

For the PA Social SW subscale, all 6 misfit items (e.g., "I still feel good about myself when I haven't stayed on my physical activity program" and "It doesn't bother me when friends tell me I need to be more active" had large Outfit values. These items may measure emotion or attitude toward to PA, not PA Social SW. Among the 8 good fit PA Social SW items, the least difficult one was "I feel bad about myself when I can't find someone to go on a walk with" and the most difficult item was "I need family to support my commitment to exercise in order to feel good about myself". Social support is one of the major contributors to PA participation in women and women with greater levels of support from loved ones (family or friends) are more likely to be active (Eyler, Wilcox, Matson-Koffman, Evenson, Sanderson, \& Thompson et al., 2002b; Eyler, Brownson, Donatelle, King, Brown, \& Sallis, 1999; Vrazel, Saunders, \& Wilcox, 2008). From a design perspective, only eight good items were retained in the PA Social SW subscale. Furthermore, the PA Social SW subscale demonstrated the weakest correlations with PA, which is not surprising because PA is complex. It is possible that not every mode of PA requires social support for participation. Duncan and colleagues (1993) reported that among six general support provisions studied, none were predictive of PA adherence. However, positive feedback or guidance from exercise instructors or other participants in an exercise program were key domain specific indicators of exercise adherence in previously sedentary women participating in an exercise program. Duncan, and colleagues (1993) also reported that emotional support or reassurance created a buffering effect with regard to exercise adherence in the women studied. Items retained for the WPASWI PA Social SW scale were related to both accessing support and support related to one's SW as it is associated with social aspects of PA participation. In an effort to add good items to the Social SW scale and to strengthen the psychometric properties of this domain of the instrument, revisions may need to include PA Social SW items related to positive feedback, guidance and emotional support related to PA Social SW and PA participation.

Information provided through item-person maps was used to determine whether the item difficulties matched the person abilities, and such information may be used to improve the WPASWI. The item-person maps for the PA Knowledge SW and PA Social SW subscales showed good item difficulty and person ability match (i.e., only 5\% or less of the sample was not covered by the item difficulty ranges), which suggests that PA Knowledge SW and PA Social SW of the majority of the women appropriately assessed well by items in the these two subscales. For the PA Emotional SW subscale, the person ability (19\%) at the highest end of the map was not covered by the item difficulty range, suggesting more difficult items are needed to better assess PA Emotional SW of those women.

Higher scores on the PA Knowledge SW and PA Emotional SW subscales of the WPASWI were consistent with higher PA participation and lower scores on these subscales were consistent with lower PA participation. These known-group differences provide additional support for construct validity of the WPASWI subscales. In addition, the three WPASWI subscales also demonstrated acceptable internal consistency as indicated by the person separation index and the reliability statistics. Additionally, test-retest reliability coefficients suggested that the WPASWI subscales are reliable instruments.

Comparisons of the WPASWI with General Self-worth of the Adult Self-Perception Profile had low correlations, supporting that the WPASWI scales assess lower-order domain-specific constructs. The General SW of the Adult Self-Perception Profile assesses global self-worth and may not have been the ideal instrument to use for criterion validity in this study. Furthermore, several researchers have reported little to no correlation between global selfesteem and PA (Gothe et al., 2011; Spence et al., 2005). This may be due to the inconsistent use of instruments, use of instruments not specifically developed for PA settings, as well as instruments that are not domain-specific (Duncan et al., 1993; Bandura, 1982; Schutzer \& Gaves, 2004). The pattern of associations observed in this study, supports the use of domain-specific SW instruments to elucidate the relationship between SW and PA (Gothe et al., 2011). We observed stronger correlations for PA Knowledge SW and PA and PA Emotional SW and PA as compared to General SW and PA. 
NOTICE: this is the author's version of a work that was accepted for publication in Psychology of Sport and Exercise. Changes resulting from the publishing process, such as peer review, editing, corrections, structural formatting, and other quality control mechanisms may not be reflected in this document. Changes may have been made to this work since it was submitted for publication. A definitive version was subsequently published in Psychology of Sport and Exercise, 2012. DOI: 10.1016/j.psychsport.2012.07.009

\section{Limitations}

There are limitations to the WPASWI that should be noted. First, items in Emotional SW subscale were not very difficult. This is not uncommon in developing instruments in social behavior science because people often tend to overestimate or report (e.g., strongly agree) on questions to meet the socially desirable norms when they really don't meet those norms. Nevertheless, the need to develop items that are more difficult to better assess differences in emotional SW in the WPASWI is clear. Second, the internal consistency of the PA Social domain was low and demonstrated poor correlation with PA participation. More research is necessary and items should be revised to increase internal consistency and relationship to PA. Third, the study sample included primarily Causation/White women, which made the comparisons between race/ethnicity difficult. The study results could be biased because the study population was lacking in racial or ethnic diversity. A further evaluation of this instrument with a more racially/ethnically diverse sample of women is needed so that the measurement invariance of WPASWI can be examined. It is important to note that this instrument was designed for women only. This is because research has shown there are differences in gender in relation to PA and its mediators (Segar, Updegraff, Zikmund-fisher, \& Richardson, 2012). Finally, although most measures supported the concept that the WPASWI is a valid instrument, criterion validity was lacking. Further research and instrument refinement is warranted

The WPASWI is the first instrument to measure non-physical SW domains related to PA (PA Knowledge, PA Emotional, and PA Social) using Rasch model analysis. The instrument demonstrated good content and construct validity. The WPASWI also had good internal consistency and test re-test reliability. More research and refinement of the instrument is needed to increase item difficulty, strengthen the Social domain, and enhance validity. The WPASWI has promise to being an instrument that health promotion professionals can use to better target domainspecific aspects of SW to increase PA participation and adherence to PA in women. 
NOTICE: this is the author's version of a work that was accepted for publication in Psychology of Sport and Exercise. Changes resulting from the publishing process, such as peer review, editing, corrections, structural formatting, and other quality control mechanisms may not be reflected in this document. Changes may have been made to this work since it was submitted for publication. A definitive version was subsequently published in Psychology of Sport and Exercise, 2012. DOI: 10.1016/j.psychsport.2012.07.009

\section{References}

Ainsworth, B.E. (2000). Physical activity patterns in women. Physician and Sports Medicine Journal, 28(10), 25-26.

Andrich, D., De Jong, J., \& Sheridan, B.E. (1997). Diagnostic opportunities with the Rasch model for ordered response categories. In J. Rost \& R. Langeheine (Eds.), Applications of latent trait and latent class models in the social sciences (59-72). Munster, Germany: Waxmann Verlag.

Baghaei, P. (2008). The Rasch Model as a construct validation tool. Rasch Measurement transactions, 22(1):11451146.

Bandura, A. (1982). Self-efficacy mechanisms in human agency. The American Psychologist. 37:122-147.

Bezruczko, N., (2005). Rasch Mesurement in Health sciences, (Ed.). Maple Grove, MN: Jam Press.

Bond, T.G., Fox, C.M. (2007). Applying the Rasch model: Fundamental measurement in the human sciences. (Ed.). Mahwah, NJ: Erlbaum.

Centers for Disease Control and Prevention (CDC). U.S. physical activity statistics. Retrieved December/2010 from http://apps.nccd.cdc.gov/PASurveillance/DemoComparev.asp

Conrad, K. J., \& Smith, E. V. (2004). International conference on objective measurement: Applications of rasch analysis in health care. Medical Care, 42(1 Suppl), I1-6.

Coopersmith, S.A. (1967). The antecedents of self-esteem. San Francisco: Freeman

Duncan, T.E., Duncan, S.C., McAuley, E. (1993). The role domain and gender-specific provisions of social relations in adherence to a prescribed exercise regimen. Journal of Sports Exercise Psychology, 15:220-231.

Duncan, P. W., Bode, R. K., Min Lai, S., Perera, S., \& Glycine Antagonist in Neuroprotection Americans Investigators. (2003). Rasch analysis of a new stroke-specific outcome scale: The stroke impact scale. Archives of Physical Medicine and Rehabilitation, 84(7), 950-963.

Elavsky, S., \& McAuley, E. (2007). Exercise and self-esteem in menopausal women: A randomized controlled trial involving walking and yoga. American Journal of Health Promotion.22(2), 83-92.

Elavsky, S. (2009). Physical activity, menopause, and quality of life: The role of affect and self-worth across time. Menopause (New York, N.Y.), 16(2), 265-271.

Eyler, A. A., Brownson, R. C., King, A. C., Brown, D., Donatelle, R. J., \& Heath, G. (1997). Physical activity and women in the united states: An overview of health benefits, prevalence, and intervention opportunities. Women \& Health, 26(3), 27-49.

Eyler, A. A., Brownson, R. C., Donatelle, R. J., King, A. C., Brown, D., \& Sallis, J. F. (1999). Physical activity social support and middle- and older-aged minority women: Results from a US survey. Social Science \& Medicine (1982), 49(6), 781-789.

Eyler, A. A., Matson-Koffman, D., Vest, J. R., Evenson, K. R., Sanderson, B., Thompson, J. L., .. . Young, D. R. (2002a). Environmental, policy, and cultural factors related to physical activity in a diverse sample of women: The women's cardiovascular health network project--introduction and methodology. Women \& Health, 36(2), 1-15.

Eyler, A. E., Wilcox, S., Matson-Koffman, D., Evenson, K. R., Sanderson, B., Thompson, J., . . Rohm-Young, D. (2002b). Correlates of physical activity among women from diverse racial/ethnic groups. Journal of Women's Health \& Gender-Based Medicine, 11(3), 239-253.

Godin, G., \& Shephard, R. J. (1985). A simple method to assess exercise behavior in the community. Canadian Journal of Applied Sport Sciences. Journal Canadien Des Sciences Appliquees Au Sport, 10(3), 141-146.

Gothe, N. P., Mullen, S. P., Wojcicki, T. R., Mailey, E. L., White, S. M., Olson, E. A., . . McAuley, E. (2011). Trajectories of change in self-esteem in older adults: Exercise intervention effects. Journal of Behavioral Medicine, 34(4), 298-306.

Harter, S. (1985). Competence as a dimension of self-evaluation: Toward a comprehensive model of self-worth. In. R.H. Leary (Ed.). The development of the self. New York: Academic Press.

Howley, E.T., \& Franks, B.D. (1992). Health fitness instructor's handbook: Health status questionnaire. Champaign, IL: Human Kinetics.

Huberty, J. L., Vener, J., Sidman, C., Meendering, J., Blissmer, B., Schulte, L., . . Ransdell, L. B. (2008a). Women bound to be active: A pilot study to explore the feasibility of an intervention to increase physical activity and self-worth in women. Women \& Health, 48(1), 83-101.

Huberty, J.L., Ransdell, L., Sidman, C., Flohr, J., Shultz, B., Grosshans, O., Durrant, L., \& Morrow, S. (2008b). Explaining long-term exercise adherence in women who complete a structured exercise program. Research Quarterly for Exercise and Sport, 79(3), 374-384.

Huberty, J. L., Vener, J., Schulte, L., Roberts, S. M., Stevens, B., \& Ransdell, L. (2009a). Women bound to be active: One year follow-up to an innovative pilot intervention to increase physical activity and self-worth in 
NOTICE: this is the author's version of a work that was accepted for publication in Psychology of Sport and Exercise. Changes resulting from the publishing process, such as peer review, editing, corrections, structural formatting, and other quality control mechanisms may not be reflected in this document. Changes may have been made to this work since it was submitted for publication. A definitive version was subsequently published in Psychology of Sport and Exercise, 2012. DOI: 10.1016/j.psychsport.2012.07.009

women. Women \& Health, 49(6), 522-539.

Huberty, J. L., Vener, J., Waltman, N., Ott, C., Twiss, J., Gross, G., . . Dwyer, A. (2009b). Development of an instrument to measure adherence to strength training in postmenopausal breast cancer survivors. Oncology Nursing Forum, 36(5), E266-73.

Huberty, J. L., Vener, J., Ransdell, L., Schulte, L., Budd, M. A., \& Gao, Y. (2010). Women bound to be active (years 3 and 4): Can a book club help women overcome barriers to physical activity and improve self-worth? Women \& Health, 50(1), 88-106. doi:10.1080/03630241003601103.

Huberty, J.L., Ehlers, D., Coleman, J., Gao, Y., \& Elavsky, S. (In Press) Women Bound to Be Active: Differences in long-term physical activity between completers and non-completers of a book club intervention. Journal of Physical Activity in Health.

Im, E. O., Lee, B., Chee, W., Stuifbergen, A., \& eMAPA Research Team. (2011). Attitudes toward physical activity of white midlife women. Journal of Obstetric, Gynecologic, and Neonatal Nursing : JOGNN / NAACOG, 40(3), 312-321.

Linacre, J.M. A User's guide WINSTEPS® MINISTEP. Rasch model computer programs (Software Manual). Retrieved 2009 from http://www.winsteps.com/winsteps.htm.

Marsh, H.W. Shavelson, R. (1985). Self concept: Its multifaceted hierarchical structure. Journal of Education Psychology, 20:107-123.

Marsh, H.W. (1988a). The Self Description Questionnaire (SDQ): A theoretic and empirical basis for the measurement of multiple dimensions of preadolescent self-concept: test manual and a research monograph. San Antonio, TX: The Psychological Association.

Marsh, H.W. (1988b). The Self Description Questionnaire (SDQ) II: A theoretic and empirical basis for the measurement of multiple dimensions of preadolescent self-concept: test manual and a research monograph. San Antonio, TX: The Psychological Association.

Marsh, H.W. (1988c). The Self Description Questionnaire (SDQ) III: A theoretic and empirical basis for the measurement of multiple dimensions of preadolescent self-concept: test manual and a research monograph. San Antonio, TX: The Psychological Association.

McAuley, E., Mihalko, S. L., \& Bane, S. M. (1997). Exercise and self-esteem in middle-aged adults: Multidimensional relationships and physical fitness and self-efficacy influences. Journal of Behavioral Medicine, 20(1), 67-83.

McAuley, E., \& Blissmer, B. (2000a). Self-efficacy determinants and consequences of physical activity. Exercise and Sport Sciences Reviews, 28(2), 85-88.

McAuley, E., Blissmer, B., Katula, J., Duncan, T. E., \& Mihalko, S. L. (2000b). Physical activity, self-esteem, and self-efficacy relationships in older adults: A randomized controlled trial. Annals of Behavioral Medicine : A Publication of the Society of Behavioral Medicine, 22(2), 131-139.

McAuley, E., Elavsky, S., Motl, R.W., Konopack, J.F., Hu, L., \& Marquez, D.X. (2005a) Physical activity, selfefficacy, and self-esteem: longitudinal relationships in older adults. Journal of Gerontology 60(5), 268-275.

McAuley, E., Blissmer, B., Katula, J., Duncan, T. E., \& Mihalko, S. L. (2005b). Physical activity, self-esteem, and self-efficacy relationships in older adults: A randomized controlled trial. Annals of Behavioral Medicine : A Publication of the Society of Behavioral Medicine, 22(2), 131-139.

Meng, X., Rosenthal, R., \& Rubin, D. B. (1992) Comparing correlated correlation coefficients. Psychological Bulletin, 111: 172-175.

Messer, B., Harter, S.V. (1986). Manual for the adult Self-perception Profile: Denver, Co: University of Denver Press.

Moore, L.V., Fulton, J., Kruger, J., McDivitt, J. (2010). Knowledge of physical activity guidelines among adults in the United States, Health styles 2003-2005. Journal of Physical Activity and Health, 7(2), 141-9.

Ransdell, L.B., Dinger, M., Huberty, J.L., \& Miller, K. (2009). Effective physical activity interventions: Guidelines for model programs. Human Kinetics.

Rasch, G. (1960). Probalistic models for some intelligence and attainment tests. Copenhagen: Danish Institute for Educational research.

Rasch, G. (1980). Probalistic models for some intelligence and attainment tests. (Ed.). Chicago: University of Chicago press.

Rosenberg, M. (1965). Society and the adolescent self-image. Princeton, NJ: Princeton University Press.

Ryan, M.P. (2008). The antidepressant effects of physical activity: Mediating self-esteem and self-efficacy variables. Psychology \& Health, 23(3):279-307.

Schutzer, K. A., \& Graves, B. S. (2004). Barriers and motivations to exercise in older adults. Preventive Medicine, 39(5), 1056-1061. 
NOTICE: this is the author's version of a work that was accepted for publication in Psychology of Sport and Exercise. Changes resulting from the publishing process, such as peer review, editing, corrections, structural formatting, and other quality control mechanisms may not be reflected in this document. Changes may have been made to this work since it was submitted for publication. A definitive version was subsequently published in Psychology of Sport and Exercise, 2012. DOI: 10.1016/j.psychsport.2012.07.009

Sallis, J.F. Hovell, M.F., Hofstetter, C.R. (1992). Predictors of adoption and maintenance of vigorous physical activity in men and women. Preventive Medicine, 21(2), 237-51.

Segar, M. L., Eccles, J. S., \& Richardson, C. R. (2008). Type of physical activity goal influences participation in healthy midlife women. Women's Health Issues, 18(4), 281-291.

Segar, M.L., Updegraff, J.A., Zikmund-Fisher, B.J., \& Richardson, C.R. (2012). Physical activity advertisements that feature daily well-being improve autonomy and body image in overweight women but not men. Journal of Obesity

Smith, E. V.,Jr. (2001). Evidence for the reliability of measures and validity of measure interpretation: A rasch measurement perspective. Journal of Applied Measurement, 2(3), 281-311.

Sonstroem, R.J, Harlow, L.L., Josephs, L. (1994). Exercise and self-esteem: Validity of model expansion and exercise associations. Journal of Sport Exercise Psychology, 16:29-42.

Sonstroem, R. J., \& Morgan, W. P. (1989). Exercise and self-esteem: rationale and model. Medicine and Science in Sports and Exercise, 21(3), 329-337.

Spence, J.C., McCannon, K.R., Poon, P. (2005). The effect of exercise on global self-esteem: A qualitative review. Journal of Sport Exercise Psychology, 27(3):311-334.

Strauss, B., Büsch, D., \& Tenenbaum, G. (2007). New developments in measurement and testing. In G. Tenenbaum \& R. Eklund (Eds.), Handbook of Sport Psychology (3rd edition). (pp.737-756). Boston, MA: Wiley.

Strauss, B., Büsch, D., \& Tenenbaum, G. (2012). Rasch modeling in Sports. In G. Tenenbaum, R. Eklund, \& A. Kamata (Eds.), Handbook of Measurement in Sports (pp. 75-80). New York: Human Kinetics.

Strelan, P, Mehaffey, S.J., Tiggeman, M. (2003). Self-objectification and esteem in youg women. Sex Roles: A Journal of Research, 89-96.

Tennant, A., McKenna, S. P., \& Hagell, P. (2004). Application of rasch analysis in the development and application of quality of life instruments. Value in Health: The Journal of the International Society for Pharmacoeconomics and Outcomes Research, 7 (1), S22-6.

U.S. Department of Health and Human Services (USDHHS). 2008 physical activity guidelines for americans. Retrieved November/2009 from http://www.health.gov/paguidelines/guidelines/chapter4.aspx.

Vrazel, J., Saunders, R. P., \& Wilcox, S. (2008). An overview and proposed framework of social-environmental influences on the physical-activity behavior of women. American Journal of Health Promotion, 23(1), 212.

Welk, G.J. (2002). Physical activity assessment in health related research. Champaign, IL: Human Kinetics.

Wells, E.L. \& Marwell, G. (1976). Self-esteem: its conceptualization and measurement. Beverly Hills, CA: Sage Publications.

Wright, B.D. \& Stone, M.H. (1988). Reliability in Rasch measurement; Research memorandum number 53. Chicago, IL: MESA press.

Wright, B.D. \& Linacre, J.M. (1994). Reasonable mean-square-fit values. Rasch Measurement Transactions, $8(3): 370$. 
NOTICE: this is the author's version of a work that was accepted for publication in Psychology of Sport and Exercise. Changes resulting from the publishing process, such as peer review, editing, corrections, structural formatting, and other quality control mechanisms may not be reflected in this document. Changes

may have been made to this work since it was submitted for publication. A definitive version was subsequently published in Psychology of Sport and Exercise, 2012. DOI: 10.1016/j.psychsport.2012.07.009

\section{Table 1}

Item Difficulty, Fit Statistics of the Knowledge SW, Emotional SW and Social SW

\begin{tabular}{|c|c|c|c|c|}
\hline Item & Difficulty & SE & Infit & Outfit \\
\hline \multicolumn{5}{|l|}{ Knowledge SW } \\
\hline I1. I value that I know how to plan a physical activity program for myself. & -0.17 & 0.12 & 1.00 & 1.00 \\
\hline I2. I like learning about physical activity and exercise. & -0.92 & 0.12 & 0.82 & 0.76 \\
\hline I3. Knowing the benefits of physical activity and exercise makes me feel better about myself. & -1.32 & 0.13 & 0.89 & 0.8 \\
\hline I4. I am good at developing physical activity programs for myself. & 1.36 & 0.11 & 1.15 & 1.19 \\
\hline I5. I learn quickly about physical activity and exercise. & -0.39 & 0.12 & 0.91 & 0.9 \\
\hline I6. The knowledge I have about physical activity and being active affects the way I feel about myself. & -0.56 & 0.12 & 0.9 & 0.86 \\
\hline I7. When I know enough about activity to decrease my risk of injury I feel better about myself. & -0.22 & 0.12 & 0.89 & 0.98 \\
\hline I8. Having an understanding of what muscle groups I use when I am physically active makes me feel good about myself. & 0.61 & 0.11 & 1.15 & 1.16 \\
\hline 19. My knowledge about physical activity contributes to my physical activity participation. & -0.21 & 0.12 & 1.07 & 1.07 \\
\hline I10. I feel better about myself knowing that I can use exercise equipment properly. & -0.37 & 0.12 & 1.03 & 1.06 \\
\hline I11. I understand how to create an environment that promotes an active lifestyle. & 0.1 & 0.12 & 0.97 & 0.94 \\
\hline I12. I value my education related to physical activity/exercise. & -0.23 & 0.12 & 0.83 & 0.77 \\
\hline I13. My knowledge about physical activity effects the way I feel about myself. & 0.47 & 0.11 & 0.98 & 1.00 \\
\hline I16. I enjoy developing a physical activity program for myself. & 1.39 & 0.11 & 1.03 & 1.07 \\
\hline I17. I am happy when I think about exercising/physical activity. & 0.68 & 0.11 & 1.05 & 1.07 \\
\hline I32. I am comfortable talking with others about physical activity and exercise. & -0.22 & 0.12 & 1.18 & 1.19 \\
\hline
\end{tabular}

\section{Emotional SW}

I18. Physical activity positively affects the way I feel about myself.

$\begin{array}{cccc}-0.65 & 0.13 & 0.9 & 0.95 \\ -0.83 & 0.13 & 0.9 & 0.78 \\ -1.63 & 0.15 & 0.74 & 0.85 \\ -0.33 & 0.13 & 1.14 & 1.1 \\ -0.39 & 0.13 & 0.91 & 0.83\end{array}$

I20. I have a greater sense of self-worth after performing physical activity.

I21. If I am physically active on a regular basis I will feel better about myself.

I22. It is important for me to take time to be physically active.

I23. I am happy when I prioritize my own needs by taking time to be physically active. 
NOTICE: this is the author's version of a work that was accepted for publication in Psychology of Sport and Exercise. Changes resulting from the publishing process, such as peer review, editing, corrections, structural formatting, and other quality control mechanisms may not be reflected in this document. Changes may have been made to this work since it was submitted for publication. A definitive version was subsequently published in Psychology of Sport and Exercise, 2012. DOI: $10.1016 /$ j.psychsport.2012.07.009

I24. I enjoy achieving my goals related to physical activity

I26. If I take time to take care of myself I will be a better, mother, wife, friend, and daughter.

I27. The support I receive for physical activity positively affects how I feel about myself.

I28. The more resources for support that I have for physical activity/exercise, the better I feel about myself.

$\begin{array}{llll}1.06 & 0.12 & 1.17 & 1.2\end{array}$

I29. I am happy when I can find the resources I need to be more active.

$\begin{array}{llll}0.41 & 0.13 & 0.88 & 0.85\end{array}$

I30. I enjoy discussing physical activity with others.

I31. Creating a supportive environment related to physical activity helps me to feel good about myself.

I45. Planning for physical activity makes me feel good about myself.

\section{Social SW}

I34. I need friends to support my commitment to exercise in order to feel good about myself.

$\begin{array}{llll}0.77 & 0.09 & 1.00 & 1.03\end{array}$

I35. I need family to support my commitment to exercise in order to feel good about myself.

$\begin{array}{llll}1.00 & 0.09 & 0.83 & 0.85\end{array}$

I36. It really bothers me that my family is not always supportive of my need to be physically active.

$\begin{array}{llll}-0.31 & 0.1 & 1.04 & 0.99\end{array}$

I37. Others don't want to join me in exercise.

I38. I really don't feel good about myself when I have to ask others for help with my physical activity program. 
NOTICE: this is the author's version of a work that was accepted for publication in Psychology of Sport and Exercise. Changes resulting from the publishing process, such as peer review, editing, corrections, structural formatting, and other quality control mechanisms may not be reflected in this document. Changes may have been made to this work since it was submitted for publication. A definitive version was subsequently published in Psychology of Sport and Exercise, 2012. DOI: 10.1016/j.psychsport.2012.07.009

Table 2. Response Format Assessment of Each Subscale

\begin{tabular}{lccc}
\hline Rating Scale Category & Category Count & Average Measure & Step Difficulty \\
\hline Knowledge SW & & & \\
Strongly Disagree (=1) & 41 & -0.71 & None \\
Disagree (=2) & 694 & 0.15 & -3.37 \\
Agree (=3) & 2845 & 1.95 & -0.39 \\
Strongly Agree (=4) & 1760 & 4.35 & 3.76 \\
Emotional SW & & & \\
Strongly Disagree (=1) & 46 & 0.46 & None \\
Disagree (=2) & 280 & 0.79 & -4.24 \\
Agree (=3) & 2045 & 2.87 & -0.23 \\
Strongly Agree $(=4)$ & 1960 & 5.69 & 4.47 \\
Social SW & & & \\
Strongly Disagree $(=1)$ & 166 & -1.43 & None \\
Disagree (=2) & 543 & -0.31 & -2.08 \\
Agree (=3) & 1489 & 0.85 & -0.74 \\
Strongly Agree $(=4)$ & 465 & 2.4 & 2.82 \\
\hline
\end{tabular}


NOTICE: this is the author's version of a work that was accepted for publication in Psychology of Sport and Exercise. Changes resulting from the publishing process, such as peer review, editing, corrections, structural formatting, and other quality control mechanisms may not be reflected in this document. Changes may have been made to this work since it was submitted for publication. A definitive version was subsequently published in Psychology of Sport and Exercise, 2012. DOI: 10.1016/j.psychsport.2012.07.009

\section{Table 3}

Person ability estimates of the Knowledge, Emotional and Social SW by PA participation and weight category

\begin{tabular}{|c|c|c|c|c|c|c|c|}
\hline \multirow[b]{2}{*}{ Variable } & \multirow{2}{*}{$\mathrm{N}$} & \multicolumn{2}{|c|}{$\begin{array}{l}\text { Knowledge } \\
\text { SW (logits) } \\
\end{array}$} & \multicolumn{2}{|c|}{$\begin{array}{c}\begin{array}{c}\text { Emotional SW } \\
\text { (logits) }\end{array} \\
\end{array}$} & \multicolumn{2}{|c|}{$\begin{array}{c}\text { Social SW } \\
\text { logits) }\end{array}$} \\
\hline & & Mean & SD & Mean & SD & Mean & SD \\
\hline Overall & 325 & 2.31 & 2.24 & 2.72 & 2.26 & 0.79 & 1.59 \\
\hline \multicolumn{8}{|l|}{$\begin{array}{l}\text { Regular leisure-time PA } \\
\text { participation }\end{array}$} \\
\hline participarion & 146 & $\begin{array}{c}3.43^{* * * a} \text {, } \\
b\end{array}$ & 2.11 & $\begin{array}{c}3.56^{* * * a,} \\
\mathrm{~b}\end{array}$ & 2.12 & $0.96^{* * * a}$ & 1.6 \\
\hline Some & 141 & $1.65^{* * * \mathrm{c}}$ & 1.96 & $2.23^{*_{\mathrm{c}}}$ & 2.12 & $0.80^{* \mathrm{c}}$ & 1.51 \\
\hline Never & 38 & 0.5 & 1.53 & 1.28 & 2.08 & 0.05 & 1.62 \\
\hline \multicolumn{8}{|l|}{ Weight Category } \\
\hline Healthy weight & 197 & 2.27 & 2.26 & 2.65 & 2.35 & $0.97 *^{\mathrm{d}}$ & 1.7 \\
\hline Overweight & 95 & 2.35 & 2.35 & 2.67 & 2.19 & 0.46 & 1.4 \\
\hline Obese & 41 & 2.29 & $\underline{1.95}$ & 2.89 & $\underline{2.05}$ & $\underline{0.85}$ & 1.38 \\
\hline
\end{tabular}

Note. "Comparison between "Often" and "Some";

"Comparison between "Often" and "Never";

"Comparison between "Some" and "Never";

"Comparison between "Healthy weight" and "Overweight";

p $<<.05$;

$* \mathrm{p}<.01$

$\mathrm{p}<.005$. 
NOTICE: this is the author's version of a work that was accepted for publication in Psychology of Sport and Exercise. Changes resulting from the publishing process, such as peer review, editing, corrections, structural formatting, and other quality control mechanisms may not be reflected in this document. Changes may have been made to this work since it was submitted for publication. A definitive version was subsequently published in Psychology of Sport and Exercise, 2012. DOI: 10.1016/j.psychsport.2012.07.009

\section{Table 4}

Pearson Correlations between Knowledge-, Emotional and Social SW and GSW and PA

\begin{tabular}{llllll}
\hline & $\begin{array}{l}\text { Knowledge } \\
\text { SW (logits) }\end{array}$ & $\begin{array}{l}\text { Emotional } \\
\text { SW (logits) }\end{array}$ & $\begin{array}{l}\text { Social SW } \\
\text { (logits) }\end{array}$ & GSW & PA \\
\hline Knowledge SW (logits) & & $.753^{* * *}$ & .092 & $.207^{* * *}$ & $.344^{* * *}$ \\
Emotional SW (logits) & & -.082 & $.130^{*}$ & $.273^{* * *}$ \\
Social SW (logits) & & & $.220^{* * *}$ & $.112^{*}$ \\
GSW & & & & $.133^{*}$
\end{tabular}

PA

$$
\begin{aligned}
& \text { Note: }{ }^{*} \mathrm{p}<.05 ; \\
& * * \mathrm{p}<.01 ; \\
& \mathrm{p}<.00
\end{aligned}
$$


